\title{
TMEM70-related mitochondrial encephalo-cardio-myopathy
}

INSERM

\section{Source}

INSERM. (1999). Orphanet: an online rare disease and orphan drug data base. TMEM70related mitochondrial encephalo-cardio-myopathy. ORPHA:1194

Mitochondrial encephalo-cardio-myopathy due to TMEM70 mutation is characterized by early neonatal onset of hypotonia, hypetrophic cardiomyopathy and apneic spells within hours after birth accompanied by lactic acidosis, hyperammonemia and 3-

methylg lutaconic aciduria. 